\title{
EVALUASI PERTUMBUHAN UJI KETURUNAN MERANTI TEMBAGA (Shorea leprosula) UMUR 12 TAHUN DI AREAL IUPHHK-HA PT. ERNA DJULIAWATI KALIMANTAN TENGAH
}

\author{
(Growth evaluation of meranti tembaga (Shorea leprosula) progeny test at twelve years old \\ IUPHHK-HA PT. Erna Djuliawati Central Kalimantan)
}

\author{
Abdurrani Muin \\ Fakultas Kehutanan Universitas Tanjungpura \\ Email : abdurrani.muin@gmail.com
}

\begin{abstract}
Meranti tembaga (Shorea leprosula) is one of the superior plants types in the application of Intensive Silviculture (SILIN) has been conducted progeny tests on the area of IUPHHK-HA PT. Erna Djuliawati in Central Kalimantan. The purpose of the study was to conduct an evaluation to determine the seedlot that superior in growth and estimate the genetic parameters, diversity and genetic progress of 12-year-old S. leprosula in the progeny test plot. The research method in the progeny test was a group randomized design experiment with the treatment of 20 seedlots that was planted in 8 groups. The data collected consisted of the tree diameter $(\mathrm{cm})$, the total tree height $(\mathrm{m})$ and the tree life percentage (\%).The results showed that in the plot of progeny test, there were 5 seedlot individuals who superior in growth. The individual seedlots are 3066, 21079, 31008, 41007, and 31003. High heritability values followed by broad genetic diversity indicate the character's appearance is more determined by genetic factors. Genetic progress value of tree diameter at medium level (8.6\%) indicates that the diameter character of the tree is supported by genetic factors, thus facilitating the progress of selection.
\end{abstract}

Keywords : Genetic variation Progeny test, Shorea leprosula, superior.

\section{Abstrak}

Meranti tembaga (Shorea leprosula) merupakan salah satu jenis tanaman unggulan dalam penerapan Silvikultur Intensif (SILIN) telah dilakukan uji keturunan pada areal IUPHHK-HA PT. Erna Djuliawati di Kalimantan Tengah. Tujuan penelitian ingin melakukan evaluasi untuk menentukan seedlot yang unggul pertumbuhannya dan menaksir parameter genetik, keragaman serta kemajuan genetik S. leprosula umur 12 tahun dalam plot uji keturunan. Metode penelitian dalam uji keturunan merupakan percobaan rancangan acak kelompok dengan perlakuan 20 seedlot yang ditanam dalam 8 kelompok. Data yang dikumpulkan terdiri dari diameter pangkal batang pohon (cm), tinggi total pohon $(m)$ dan persentase hidup pohon (\%). Hasil penelitian menunjukkan bahwa dalam plot uji coba keturunan, terdapat 5 individu seedlot yang unggul pertumbuhannya. Seedlot yang unggul secara individu tersebut adalah 3066, 21079, 31008, 41007, dan 31003. Nilai heritabilitas yang tinggi diikuti dengan keragaman genetik yang luas menunjukkan penampilan karakter tersebut lebih ditentukan oleh faktor genetik. Nilai kemajuan genetik diameter pohon yang berada pada tingkat sedang $(8,6 \%)$ mengindikasikan bahwa karakter diameter pohon tersebut didukung oleh faktor genetik, sehingga dapat memfasilitasi kemajuan seleksi.

Kata kunci : S. leprosula, Uji Keturunan, unggul, variasi genetik. 


\section{PENDAHULUAN}

Indonesia memiliki hutan tropis yang cukup luas dengan keanekaraman jenis vegetasi hutan yang cukup tinggi. Meranti tembaga (Shorea leprosula Miq.) merupakan salah satu marga shorea dari famili dipterocarpaceae yang tumbuh dominan di hutan tropis Indonesia. Menurut Pamoengkas dan Prasetia (2014) meranti tembaga ( $S$. leprosula) termasuk jenis tanaman yang cepat tumbuh di Kalimantan dan memiliki struktur batang pohon yang lurus serta silindris sehingga banyak digunakan sebagai bahan baku produksi kayu lapis, kayu mebel, maupun kayu pertukangan lainnya. Keunggulan lain bahwa meranti tembaga (S. leprosula Miq.) termasuk salah satu jenis dari famili dipterocarpaceae yang tergolong cepat tumbuh, sehingga sangat potensial untuk rehabilitasi dan pembinaan hutan alam. Berdasarkan hasil penelitian Pamoengkas dan Prayogi (2011) bahwa tanaman $S$. leprosula yang ditanam dalam jalur TPTJ memperlihatkan perkembangan yang cepat. Hasil penelitiannya menunjukkan rata-rata diameter tanaman pada umur 9 tahun sudah mencapai hampir $20 \mathrm{~cm}(19,70 \mathrm{~cm})$ dan riap (MAI) sekitar 2,19 cm/tahun dengan pohon berdiameter terbesar mencapai 28.5 $\mathrm{cm} \quad(\mathrm{MAI}=3.16 \mathrm{~cm} /$ tahun$)$. Keunggulan pertumbuhan dan pemanfaatnyannya tersebut menyebabkan meranti tembaga $(S$. leprosula) merupakan salah satu jenis yang direkomendasikan untuk kegiatan penanaman dalam penerapan silvikultur intensif (SILIN).

Silvikultur Intensif (SILIN) adalah teknik silvikultur yang memadukan pemuliaan pohon, manipulasi lingkungan, dan pengelolaan organisme pengganggu tanaman (OPT) dalam suatu tegakan dan lingkungannya untuk mengakselerasi pertumbuhan tanaman. Salah satu pilar dari pelaksanakan pemuliaan dalam SILIN adalah penggunaan jenis meranti yang berasal dari bibit unggul. Dalam rangka penyediaan benih unggul tanaman meranti tembaga untuk pelaksanaan SILIN, maka PT. Erna Djuliawati telah melakukan kegiatan pemuliaan dengan membangun plot uji keturuan meranti tembaga (Shorea leprosula Miq) dalam areal IUPHHK-HA di Kalimantan Tengah. Tujuan Pembangunan plot uji keturunan selain untuk dimanfaatkan sebagai populasi pengujian genetik pada uji keturunan berikutnya, juga akan digunakan sebagai populasi penghasil benih unggul. Plot uji keturunan dapat digunakan sebagai populasi penghasil benih unggul setelah melalui serangkaian penjarangan seleksi berdasarkan parameter genetik (Handayani et al., 2017). Selain itu, berdasarkan data yang diperoleh akan dilakukan analisis keragaman dan heritabilitas pohon meranti merah (S. leprosula) yang ditanam pada plot uji keturunan tersebut. Acquaah (2012) mengemukakan bahwa keragaman genetik dan heritabilitas merupakan syarat mutlak dalam keberhasilan suatu program pemuliaan tanaman dan memperbesar kemungkinan untuk mendapatkan genotip yang lebih baik melalui seleksi. Keragaman karakter dan keanekaragaman genotip berguna untuk mengetahui pola pengelompokan genotip pada populasi tertentu berdasarkan karakter yang diamati 
dan dapat dijadikan sebagai dasar kegiatan seleksi (Agustina dan Waluyo, 2017).

Penelitian ini bertujuan mengevaluasi pertumbuhan untuk menentukan seedlot unggul dan menaksir parameter genetik yang meliputi heritabilitas, keragaman serta kemajuan genetik meranti tembaga $(S$. Leprosula) umur 12 tahun dalam plot uji keturunan (progeny test) IUPHHK-HA PT. Erna Djuliawati Kalimantan Tengah. Hasil penelitian diharapkan dapat dijadikan sebagai evaluasi untuk menggunakan sumber benih unggul dari pohon-pohon hasil uji keturunan (progeni test) berikutnya dan sebagai sumber benih untuk penanaman dalam rangka melaksanakan teknik SILIN di areal IUPHHK-HA PT. Erna Djuliawati.

\section{METODE PENELITIAN}

\section{Waktu dan Tempat Penelitian}

Penelitian dilaksanakan pada plot uji keturunan meranti tembaga (S. leprosula) berumur 12 tahun di areal IUPHHK-HA PT. Erna Djuliawati di Provinsi Kalimantan Tengah pada bulan Januari 2020. Secara geografis PT Erna Djuliawati terletak pada bentang 0052 'е $30 "-0122^{\text {‘e } 30 " ~ L S, ~ d a n ~}$ $11130^{\text {ee }} 00$ "- $11207^{\text {ec } 30 " ~ B T ~ p a d a ~}$ ketinggian antara 111-1.082 mdpl, dengan topografi berkisar antara datar dan berbukit. Teknik Pengumpulan dan Analisis Data Teknik pengumpulan data

Data yang dikumpulkan terdiri dari atas diameter pohon $(\mathrm{cm})$, tinggi pohon (m), dan pesentase hidup pohom yang dilakukan oleh PT. Erna Djuliawati sejak ditanam pada tahun 2007 sampai umur tanaman 12 tahun. Diameter pohon diukur pada tinggi 1,20 $\mathrm{m}$ dari tanah dan tinggi total pohon. Persentase hidup dihitung berdasarkan jumlah pohon yang hidup dibagi dengan jumlah pohon yang ditanam dikali $100 \%$.

\section{Analisis data}

\section{1) Keragaman (variasi) pertumbuhan}

Untuk menentukan adanya variabilitas yang terjadi di antara faktor pertumbuhan pohon, dilakukan analisis keragaman terhadap diameter, tinggi dan persentase hidup pohon umur 12 tahun. Model umum analisis varians menurut Kinho et al. (2015) yang disesuaikan dengan seedlot uji coba keturunan di areal IUPHHK-HA PT. Erna Djuliawati adalah

$\mathrm{Y}_{\mathrm{ijk}}=\mu+\mathrm{S}_{\mathrm{i}}+\mathrm{B}_{\mathrm{j}}+\mathrm{SB}_{\mathrm{ij}}+\varepsilon_{\mathrm{ijk}}$

Keterangan:

$\mathrm{Y}_{\mathrm{ijk}}=$ pengamatan tanaman ke-k pada famili ke-i dalam blok ke-J

$\mu=$ rerata umum

$\mathrm{S}_{\mathrm{i}} \quad=$ pengaruh Seedot

$\mathrm{B}_{\mathrm{j}} \quad=$ pengaruh blok ke- $\mathrm{j}$

$\mathrm{SB}_{\mathrm{ij}}=$ interaksi seedlot ke-i dan blok ke-j

$\varepsilon_{\mathrm{ijk}}=$ random error (Galat)

Untuk mengetahui pengaruh seedlot, blok, dan interaksi seedlot dengan blok serta pengaruh genetik terhadap variabilitas pertumbuhan di antara seedlot (famili) yang diuji, maka dilakukan analisis keragaman rencangan acak kelompok.

2) Nilai duga Heritabilitas $\left(h^{2}\right)$

Nilai dugaaan heritabilitas $\left(\mathrm{h}^{2}\right)$ dihitung menggunakan rumus heritabilitas dalam arti luas (Lasmono et al., 2018) yang diturunkan dari sidik ragam berikut ini.

$$
\begin{aligned}
\sigma^{2} \mathrm{e} & =\frac{\mathrm{KTe}}{\mathrm{r}} \\
\sigma^{2} \mathrm{~g} & =\mathrm{KTg}-\sigma^{2} \mathrm{e} \\
\sigma^{2} \mathrm{p} & =\sigma^{2} \mathrm{~g}+\sigma^{2} \mathrm{e} \\
\mathrm{h}^{2} & =\frac{\sigma^{2} \mathrm{~g}}{\sigma^{2} \mathrm{p}}
\end{aligned}
$$

Keterangan :

$\mathrm{h}^{2}=$ Heritabilitas 


$$
\sigma^{2} \mathrm{e}=\text { ragam lingkungan }
$$

$\sigma^{2} \mathrm{~g}=$ ragam genetik

$\sigma^{2} \mathrm{p}=$ ragam fenotip

Menurut Wardani et al. (2015) nilai heritabilitas dalam arti luas dinyatakan dalam desimal antara $0-1$ dengan kriteria nilai sebagai berikut: tinggi bila nilai $\mathrm{H}>0,5$, sedang bila nilai $0,2<\mathrm{H}-\leq 0,5$, dan rendah bila nilai $\mathrm{H} \leq 0,2$.

\section{3) Keragaman genetik dan fenotip}

Keragaman genetik dan fenotip dihitung dengan menggunakan standar error ragam genetik dan standar error ragam fenotip mengikuti rumus yang dikemukakan oleh Anderson dan Bancroff (1952) dalam Lasmono et al. (2018). Rumus untuk keragaman genetik dan keragaman fenotip adalah sebagai berikut.

$$
\begin{aligned}
& \sigma^{2} \mathrm{~g}=\sqrt{\frac{2}{r 2}\left[\frac{K T 2^{2}}{\text { db genotipe }+2}+\frac{K T 1^{2}}{\text { db galat }+2}\right]} \\
& \sigma^{2} \mathrm{p}=\sqrt{\frac{2}{r 2}\left[\frac{K T 2^{2}}{\text { db genotipe }+2}\right]}
\end{aligned}
$$

Keragaman genetik dikatakan luas jika nilai $\sigma^{2} \mathrm{~g} \geq 2$ dan dinyatakan sempit jika $\sigma^{2} \mathrm{~g} \leq 2$. Keragaman fenotipik dikatakan luas jika $\sigma^{2} \mathrm{p} \geq 2$ dan dinyatakan sempit jika $\sigma^{2} \mathrm{p} \leq 2$ (Wardani et al, 2015). Kemajuan genetik harapan (KGH) menggunakan rumus sebagai berikut (Falconer, 1989 dalam Lasmono et al., 2018).

$$
\begin{aligned}
& \mathrm{KGH}=\mathrm{i} . \mathrm{h}^{2} . \Sigma \mathrm{p} \\
& \% \mathrm{KGH}=\frac{\mathrm{KGH}}{\mu} \mathrm{X} \\
& 100 \%
\end{aligned}
$$

Dimana $: \mathrm{KGH}=$ Kemajuan Genetik Harapan

$\mathrm{i}=$ Intensitas seleksi $10 \%(1.76)$

$\mathrm{h}^{2}=$ Nilai hertabilitas

$\sigma p=$ Simpangan baku fenotip

$\mu=$ Nilai rata-rata populasi

\section{HASIL DAN PEMBAHASAN}

\section{Pertumbuhan Tanaman}

Berdasarkan hasil pengukuran diameter dan tinggi tanaman, diketahui bahwa tingkat pertumbuhan tanaman uji keturunan S. leprosula di plot uji keturunan IUPHHK-HA PT. Erna Djuliawati adalah : tinggi pohon rata-rata16,6 m dengan ukuran tertingi $18,28 \mathrm{~m}$ dan terendah $15,28 \mathrm{~m}$. Diameter batang (dbh) rata-rata $25,28 \mathrm{~cm}$ dengan ukuran terbesar 29,46 cm dan terkecil 22,93 cm. Persentase hidup pohon uji coba berkisar antara 66,14 sampai $85,63 \%$. Hasil rata-rata rangking secara kelompok terhadap ukuran diameter, tinggi pohon dan persentase hidup pohon sebagaimana disajikan pada Tabel 1, ternyata secara kelompok pohon dalam plot uji coba tersebut terdapat 15 seedlot yang unggul (superior) pertumbuhannya. 
Tabel 1. Rata-rata ukuran diameter, tinggi, volume dan persentase seedlot S. leprosula yang unggul secara kelompok pada umur 12 tahun (The mean of diameter, height, and percentage of superior seedlot S. leprosula at the age of 12 years)

\begin{tabular}{ccccc}
\hline No & Seedlot & Diameter $(\mathrm{cm})$ & Tinggi $(\mathrm{m})$ & \% Hidup \\
\hline 1 & 21074 & 26,50 & 18,28 & 79,00 \\
2 & 41007 & 27,46 & 15,86 & 83,63 \\
3 & 31010 & 26,54 & 15,14 & 66,14 \\
4 & 3066 & 27,60 & 15,72 & 78,00 \\
5 & 31003 & 25,62 & 16,11 & 80,63 \\
6 & 21081 & 26,81 & 16,41 & 73,71 \\
7 & 3227 & 26,54 & 16,19 & 84,29 \\
8 & 21002 & 26,58 & 16,42 & 82,63 \\
9 & 3232 & 27,01 & 15,72 & 69,75 \\
10 & 21073 & 26,12 & 16,07 & 85,63 \\
11 & 21082 & 26,46 & 15,92 & 75,38 \\
12 & 31005 & 25,89 & 16,13 & 84,25 \\
13 & 41008 & 25,93 & 16,00 & 81,63 \\
14 & 21075 & 24,34 & 15,92 & 77,14 \\
15 & 21079 & 25,82 & 15,67 & 81,29 \\
\hline
\end{tabular}

Dalam program pemuliaan, rangking pertumbuhan merupakan faktor yang sangat penting, karena merupakan ukuran kemampuan tumbuh seedlot yang diuji dalam uji keturunan. Kinho et al (2015) secara umum mengemukakan bahwa rangking famili biasanya didasarkan atas sifat yang diinginkan, misalnya tinggi, diameter, berat jenis, produksi getah, tipe percabangan, dan bentuk batang. Seleksi pada pohon uji keturunan di areal PT. Erna Djuliawati dapat dilakukan terhadap pohon yang unggul secara individu. Hasil seleksi terhadap 15 pohon yang unggul secara kelompok, ternyata dapat diperoleh 5 seedlot yang unggul secara individu seperti terlihat pada Tabel 2.

Tabel 2. Lima individu seedlot $S$. leprosula dalam uji keturunan yang unggul pada umur 12 tahun (Five individual S. leprosula seedlots superior in the porgeny test at 12 years old)

\begin{tabular}{cccccccc}
\hline \multirow{2}{*}{ No } & \multirow{2}{*}{ Seedlot } & Tinggi & Diameter & \multicolumn{4}{c}{ Posisi Tanaman } \\
\cline { 5 - 8 } & & total $(\mathrm{m})$ & $(\mathrm{cm})$ & Blok & Jalur & Ajir & No Pohon \\
\hline 1 & 3066 & 23,38 & 47,5 & I & V & 10 & 2 \\
2 & 21079 & 25,75 & 34,4 & III & VI & 13 & 1 \\
3 & 31008 & 22,05 & 36,6 & III & III & 11 & 3 \\
4 & 41007 & 21,35 & 37,6 & I & II & 11 & 3 \\
5 & 31003 & 18,30 & 39,7 & I & II & 10 & 2 \\
\hline
\end{tabular}

Pada Tabel 2 terlihat pertumbuhan seedlot 3066 secara individu lebih unggul pertumbuhan diameter pohon dibandingkan dengan keempat seedlot lainnya. Seedlot
21079 lebih unggul pertumbuhan tingginya dibandingkan dengan seedlot 3066, 31008, 41007 dan 31003. Berdasarkan uji Duncan Multiple Range Test (DRMT), seedlot 3006 
dan 21079 tidak berbeda nyata dalam hal pertumbuhan diameter dan tinggi, namum berbeda nyata dengan seedlot 31008, 41007 dan 31003. Jika dilihat laju pertumbuhan dari tanaman mulai umur 1 tahun, terlihat bahwa fenotip tinggi mengalami stagnan pada umur 6 tahun. Pertumbuhan tinggi yang stagnan ini mengindikasikan terjadi persaingan tajuk, sehingga perlu tindakan pemeliharaan berupa penjarangan. Seedlot yang kurang baik pertumbuhannya sudah harus disisihkan untuk memberikan ruang tumbuh yang baik bagi seedlot yang unggul dan mencegah terjadinya penyerbukan silang, sehingga akan diperoleh seedlot yang betul-betul unggul sebagai pohon induk.

Sebagai seedlot yang unggul, selain bisa dijadikan sebagai sumber bibit untuk pemuliaan, juga kegiatan penanaman pengayaan meranti tembaga (S. leprosula) pada areal IUPHHK-HA PT. Erna Djuliawati. Namun jika dijadikan sebagai sumber benih, maka harus dilakukan pemeliharaan dan penjarangan. Menurut Sumardi et al. (2018) pembangunan plot uji keturunan selain dimanfaatkan sebagai populasi pengujian genetik untuk mengetahui parameter genetik, juga akan digunakan sebagai populasi penghasil benih unggul. Plot uji keturunan dapat digunakan sebagai populasi penghasil benih unggul setelah melalui serangkaian penjarangan seleksi berdasarkan parameter genetik (Handayani et al., 2017). Surip et al. (2017) menyatakan bahwa proses seleksi akan diarahkan untuk mendapatkan perolehan genetik yang optimal dan mencegah kemungkinan terjadinya kehilangan potensi perolehan genetik (loss potential genetic gain).

\section{Analisis Keragaman (Varians)}

Data pertumbuhan selanjutnya dianalisis menggunakan analisis keragaman yang hasilnya disajikan pada Tabel 3. Hasil tersebut menunjukkan terdapat variasi pertumbuhan seedlot yang signifikan terhadap pertumbuhan pada tinggi, diameter dan persentase hidup. Diduga asal sumber benih setiap seedlot tanaman (provenance) berpengaruh nyata pada semua karakter yang diamati. Menurut Nocetti et al. (2011) bahwa asal provenan sangat berpengaruh terhadap pertumbuhan tanaman. Pengaruh lingkungan pada penelitian ini masih kuat yang ditandai dengan pertumbuhan seedlot yang berbeda secara signifikan antar blok. Perbedaan tingkat pertumbuhan dan persentase hidup pada blok diduga karena jarak tanaman yang sudah berbeda. 
Tabel 3. Hasil analisis keragaman diameter, tinggi dan persentase hidup tanaman uji keturunan (The diversity results analysis of diameter, height and plant life percentage of $S$. leprosula in the progeny test)

\begin{tabular}{|c|c|c|c|c|c|c|}
\hline No & Parameter dan KK & SK & $\mathrm{Db}$ & JK & KT & F- Hit \\
\hline \multirow{3}{*}{1} & \multirow{3}{*}{$\begin{array}{l}\text { Diameter } \\
\mathrm{KK}=23,08 \%\end{array}$} & Blok (B) & 7 & 1911,50 & 273,07 & 2,00 \\
\hline & & Seedlot (S) & 29 & 6443,13 & 222,18 & $1,63 *$ \\
\hline & & Interaksi (B x S) & 203 & 44946,44 & 221,41 & $1,62 * *$ \\
\hline \multirow{5}{*}{2} & \multirow{5}{*}{$\begin{array}{l}\text { Tinggi } \\
\mathrm{KK}=20,91 \%\end{array}$} & Blok (B) & 7 & 6148,42 & 878,35 & $15,34 * *$ \\
\hline & & Seedlot (S) & 29 & 2799,38 & 96,53 & $1,69 *$ \\
\hline & & Interaksi (B x S) & 203 & 15607,99 & 76,89 & $1,34 * *$ \\
\hline & & Seedlot (S) & 29 & 5,14 & 0,18 & $1,56^{*}$ \\
\hline & & Interaksi (B x S) & 203 & 43,10 & 0,21 & $1,86 * *$ \\
\hline \multirow{3}{*}{3} & \multirow{3}{*}{$\begin{array}{l}\text { Persentase Hidup } \% \\
\mathrm{KK}=33,19 \%\end{array}$} & Blok (B) & 7 & 529,15 & 75,59 & $5,43 * *$ \\
\hline & & Seedlot (S) & 29 & 539,90 & 18,62 & 1,34 \\
\hline & & Interaksi (B x S) & 203 & 351,26 & 1,73 & 0,12 \\
\hline
\end{tabular}

Perbedaan laju pertumbuhan tinggi dan diameter tanaman pada S. leprosula di plot uji keturunan PT. Erna Djuliawati juga terlihat dari tingkat variasi fenotipik yang muncul. Nilai koefisien variasi diameter lebih besar dibandingkan dengan nilai koefisien variasi pada tinggi tanaman (Tabel 3) mengindikasikan bahwa faktor penghambat pertumbuhan tanaman adalah kondisi jarak tanam yang sudah berbeda. Perbedaan jarak sebagai akibat selama proses pertumbuhannya, karena sejumlah pohon ada yang mati. Tanaman S. leprosula yang terdapat dalam plot uji keturunan dapat dikategorikan sebagai tegakan seumur karena ditanam pada waktu yang bersamaan dengan jarak tanam yang sama. Pohon yang masih rapat karena persentase hidupnya rendah menekan munculnya ekspresi variasi fenotipik tinggi tanaman, sehingga variasi tinggi tanaman rendah. Sementara itu pada blok dengan jumlah persentase kematian tinggi, lemahnya efek kompetisi tanaman $S$. leprosula rendah telah meningkatkan munculnya ekspresi variasi fenotipik yang lebih besar pada diameter batang. Topografi tidak berpengaruh terhadap variasi fenotifik terdadap tinggi, karena blok tanaman ditempatkan pada kelerengan dibawah $25 \%$. Hasil penelitian Sari dan Karmilasanti (2015) di Kalimantan Timur menunjukkan bahwa jenis $S$. leprosula tumbuh pada kelas kelerengan $8-15 \%, \quad 15-25 \%, \quad 25-40 \%$ dan $>40 \%$. Dalam hal kelas kelerengan untuk S. leprosula menurutnya terlihat tumbuh pada kelas kelerengan yang ekstrim yaitu $>40 \%$.

\section{Hasil Uji Heritabilitas, Keragaman Genetik dan Fenotip}

\section{Heritabilitas}

Heritabilitas merupakan penduga yang penting dari derajat respons suatu populasi terhadap seleksi alami maupun seleksi buatan. Heritabilitas merupakan parameter genetik yang digunakan untuk mengukur kemampuan genotip populasi tanaman dalam mewariskan karakter yang dimilikinya (Meena et al., 2016). Hasil perhitungan heritabilitas, variabilitas dan kemajuan genetik dikemukakan pada Tabel 4. 
Tabel 4. Hasil uji hertabilitas dan variabilitas genetik uji keturunan Shorea leprosula (Results of hertability test and genetic variability of S. leprosula in the progeny test)

\begin{tabular}{ccccccc}
\hline \multirow{2}{*}{ Nomor } & $\begin{array}{c}\text { Variabel yang } \\
\text { diamati }\end{array}$ & $\mathrm{H}^{2}$ & \multicolumn{2}{c}{ Variabilitas } & \multicolumn{2}{c}{ Kemajuan Genetik } \\
& \multicolumn{1}{c}{$\sigma \sigma^{2} G$} & $\sigma \sigma^{2} p$ & $\mathrm{KGH}$ & $\%$ KGH \\
\hline 1 & Diameter $(\mathrm{cm})$ & 0,71 & 1,75 & 1,74 & 2,17 & $8,6 \%$ \\
2 & Tinggi $(\mathrm{m})$ & 0,66 & 0,76 & 0,75 & 0,87 & $5,5 \%$ \\
\hline
\end{tabular}

Hasil perhitungan nilai heritabilitas $\left(\mathrm{h}^{2}\right)$ sebesar 0,71 (diameter) dan 0,66 (tinggi) pada Tabel 4 lebih dari 0,5 yang berati cukup tinggi. Nilai heritabilitas yang tinggi (lebih dari 0,5) menunjukkan bahwa pertumbuhan $S$. leparosula pada plot uji coba keturunan lebih besar dipengaruhi oleh faktor genetik. Heritabilitas dengan nilai yang tinggi mengindikasikan bahwa faktor genetik memberikan pengaruh yang cukup kuat terhadap variasi sifat pertumbuhan tinggi dan diameter dalam plot uji coba. Nilai heritabilitas yang tinggi menjelaskan bahwa faktor genetik merupakan faktor yang berpengaruh terhadap variasi tinggi dan diameter berkisar antara 0 - 1 . Menurut Jameela et al. (2014) nilai heritabilitas tinggi menunjukkan bahwa keragaman yang muncul untuk karakter-karakter tersebut lebih dipengaruhi oleh faktor genetik dibandingkan dengan faktor lingkungan. Handayani dan Hidayat (2012) juga mengemukakan bahwa nilai heritabilitas yang tinggi menunjukkan tingkat hubungan antara fenotip dan genotip yang tinggi, dalam hal ini faktor genetik mempunyai pengaruh yang lebih besar daripada faktor lingkungan terhadap penampilan suatu karakter atau fenotip. Hasil penelitian (Erwi et al., 2015) menunjukkan bahwa nilai heritabilitas yang tinggi pada tanaman gaharu (Aquilaria malaccensis Lamk) membuktikan faktor genetik lebih berperan. Faktor genetik yang tinggi pada tanaman $S$. leprosula dapat menentukan seleksi pada generasi awal dan seedlot mana yang akan dipilih sebagai pohon induk dengan kualitas yang terbaik pada demplot uji keturunan tersebut.

\section{Keragaman genetik dan fenotip}

Hasil perhitungan keragaman genetik tanaman $S$. leprosula pada plot uji keturunan areal IPHHHK-HA PT. Erna Djuliawati dapat dilihat pada Tabel 4. Dari hasil perhitungan, ternyata keragaman genetik dan fenotip diameter dan tinggi tanaman S. leprosula pada plot uji keturunan tersebut sempit karena lebih kecil dari 2. Nilai keragaman S. leprosula yang sempit ini diduga karena materi genetik dalam percobaan ini merupakan galur yang tidak murni pada generasi F-1 yang belum homozigot. Menurut Pinaria et al. (1995), keragaman genetik suatu populasi tergantung pada latar belakang genetik segregasi dan tingkat generasinya. Jameela et al. (2014) mengemukakan pada generasi $F_{2}$ tanaman akan mengalami segregasi sesuai dengan hukum Mendel sehingga akan menyebabkan keragaman menjadi luas. Keragaman genetik suatu populasi tergantung pada apakah populasi tersebut merupakan generasi bersegregasi dari suatu persilangan, pada generasi ke berapa, dan bagaimana latar belakang genetiknya (Pinaria et al., 1995).

Nilai duga kemajuan genetik harapan pada populasi S. leprosula $\mathrm{F}_{1}$ (Tabel 4) adalah tinggi pada karakter untuk diameter. Hal ini disebabkan karena karakter kuantitatif yang diuji juga memiliki nilai heratibilitas yang 
cukup tinggi terutama diameter, meskipun agak rendah pada tinggi pohon. Tingginya nilai kemajuan genetik dalam suatu karakter mengindikasikan karakter tersebut didukung oleh faktor genetik, sehingga dapat memfasilitasi kemajuan seleksi. Nilai heritabilitas yang tinggi suatu karakter yang diikuti dengan keragaman genetik yang luas menunjukkan penampilan karakter tersebut lebih ditentukan oleh faktor genetik. Keragaman genetik seedlot dengan nilai yang berbeda-beda menunjukkan keragaman pohon induk dan sistem perkawinan yang terjadi pada masing-masing populasi. Menurut Sulistyawati et al. (2014) nilai keragaman genetik seperti yang terjadi pada anakan $S$. leprosula yang berbeda-beda menunjukkan keragaman pohon induk dan sistem perkawinan yang terjadi pada masing-masing populasi.

\section{KESIMPULAN DAN SARAN}

Berdasarkan ukuran diameter dan tinggi pohon secara kelompok terdapat 15 seedlot yang unggul dalam uji coba keturunan PT. Erna Djuliawati. Secara individu terdapat lima seedlot yang unggul yakni seedlot 3066, 21079, 31008, 41007 dan 31003 yang terletak pada blok I dan III dalam plot uji coba. Kelima seedlot ini bisa dijadikan sebagai pohon induk untuk kegiatan pemuliaan (uji keturunan) dan sumber benih pelaksanaan teknik SILIN.

Hasil analisis keragaman (varians) terhadap diameter pohon, tinggi dan persentase hidup pohon menunjukkan adanya perbedaan yang nyata di antara seedlot yang diuji terhadap sifat yang diukur. Hal ini memperlihatkan adanya variasi yang tinggi diantara parameter yang diukur, sehingga memungkinkan dilakukan seleksi untuk menghasilkan peningkatan perolehan genetik yang tinggi.
Nilai hertabilitas yang tinggi (lebih dari $0,5)$ menunjukkan bahwa pertumbuhan $S$. leparosula pada plot uji coba keturunan lebih besar dipengaruhi oleh faktor genetik. Nilai heritabilitas tinggi juga menunjukkan bahwa keragaman yang muncul untuk karakterkarakter tersebut lebih dipengaruhi oleh faktor genetik dibandingkan dengan faktor lingkungan.

Berdasarkan hasil perhitungan keragaman genetik tanaman tembaga ( $S$. leprosula) pada plot uji keturunan areal IUPHHK-HA PT. Erna Djuliawati, ternyata keragaman genetik dan fenotip diameter dan tinggi tanaman $S$. leprosula pada plot uji keturunan tersebut sempit karena lebih kecil dari 2. Nilai kemajuan genetik diameter sedang $(8,6 \%)$ mengindikasikan karakter diameter tersebut didukung oleh faktor genetik, sehingga dapat memfasilitasi kemajuan seleksi.

Ucapan terima kasih kepada PT. Erna Djuliawati yang telah memfasilitasi kegiatan penelitian dengan judul EVALUASI PERTUMBUHAN TANAMAN UJI KETURUNAN MERANTI TEMBAGA (Shorea leprosula) UMUR 12 TAHUN DI AREAL IUPHHK-HA PT. ERNA DJULIAWATI KALIMANTAN TENGAH

\section{DAFTAR PUSTAKA}

Acquaah G. 2012. Principles of Plant Genetics and Breeding. Second Edition. Wiley-Blackwell. 740 pp.

Agustina NI, dan Waluyo B. (2017). Keragaman Karakter Morfo-agronomi Jurnal Agro 5(1), 201837 dan keanekaragaman galur- galur cabai besar (Capsicum annuum L.). Jurnal Agro 4(2) : 120-130.

Erwi L, Muin A, Burhanuddin. 2015. Uji Heritabilitas Gaharu (Aquilaria malaccensis Lamk) Umur Empat 
Tahun Pada Demplot Dinas Kehutanan Kabupaten Ketapang. Jurnal Hutan Lestari 3 (2) : 300 - 312.

Handayani T dan Hidayat IM. 2012. Keragaman Genetik dan Heritabilitas Beberapa Karakter Utama Pada Kedelai Sayur dan Implikasinya Untuk Seleksi Perbaikan Produksi. J. Hort. 22(4) : 327-333.

Handayani BR, Sunarti S, and Nirsatmanto A. 2017. Selection and Genetic Gain In Third Generation Seedling Seed Orchard of Acacia Mangium. Jurnal Pemuliaan Tanaman Hutan 11(1) : 5766.

Jameela H dan Soegianto A. 2014. Keragaman Genetik dan Heritabilitas Karakter Komponen Hasil Pada Populasi $\mathrm{F}_{2}$ Buncis (Phaseolus vulgaris L.) Hasil Persilangan Varietas Introduksi Dengan Varietas. Jurnal Produksi Tanaman $2(4)$ : $324-329$.

Kinho J, Halawane J, Irawan A, dan Kafiar Y. 2015. Evaluasi Pertumbuhan Tanaman Uji Keturunan Eboni (Diospyros Rumphii) Umur Satu Tahun di Persemaian. Pros Sem Nas Masy Biodiv Indon 1(4) : 800-804

Lasmono G, Sugiharto AN dan Respatijarti. 2018. Pendugaan Nilai Heritabilitas, Keragaman Genetik dan Kemajuan Genetik Harapan Pada Beberapa Genotipe F5 Cabai (Capsicum annuum L.). Jurnal Produksi Tanaman 6(4) : 668-677.

Meena M, Kumar N, Meena JK, dan Rai T. 2016. Genetic Variability, Heritability and Genetic Advance in Chilli (Capsicum annuum). Bioscience Biotechnology Reaserch Communications, 9(2), 258-262.

Nadhifah A, Suratman dan Pitoyo A. 2016. Kekerabatan Fenetik Ciplukan (Physalis angulata L.) Di Wilayah Eks-
Karesidenan Surakarta Berdasarkan Karakter Morfologis, Palinologis dan Pola Pita Isozim. Jurnal Tumbuhan Obat Indonesia 9(1) : 1 -10.

Nocetti M, Rozenberg P, Chaix G and Macchioni N. 2011. Provenance Effecton The Ring Structure of Teak (Tectona grandis L.f.) Wood by X-ray Micro Densitometry. Annals Forest Science 68: 1375-1383.

Pamoengkas P dan Prasetia R. 2014. Pertumbuhan Meranti Merah (Shorea leprosula Miq) Dalam Sistem Tebang Pilih Tanam Jalur Di Areal IUPHHKHA PT. SARPATIM, Kalimantan Tengah. Jurnal Silvikultur Tropika 05(3) : 174-180.

Pamoengkas P dan Prayogi J. 2011. Pertumbuhan Meranti Merah (Shorea leprosula Miq) Dalam Sistem Silvikultur Tebang Pilih Tanam Jalur (Studi Kasus di Areal IUPHHK-HA PT. Sari Bumi Kusuma, Kalimantan Tengah). Jurnal Silvikultur Tropika 02(01) : $9-13$

Pinaria A, Baihaki A, Setiamihardja R, dan Daradjat AA. 1995. Variabilitas Genetik dan Heritabilitas KarakterKarakter Biomassa 53 Genotipe Kedelai. Jurnal Zuriat 6(2): 88-92.

Sari N dan Karmilasanti. 2015. Kajian Tempat Tumbuh Jenis Shorea smithiana, $S$. johorensis dan $S$. leprosula Di PT. ITCI Hutani Manunggal, Kalimantan Timur. Jurnal Penelitian Ekosistem Dipterokarpa 1(1) : 15 - 28

Rosmaina, Syafrudin, Hasrol, Yanti F, Juliyanti dan Zulfahmi. 2016. Estimation of variability, heritability and genetic advance among local chili pepper genotypes cultivated in peat lands. Bulgarian Journal of Agricultural Science 22(3) : 431-436. 
Sulistyawati P, Widyatmoko AYPBC dan Nurtjahjaningsih ILG. 2014. Keragaman Genetik Anakan Shorea leprosula Berdasarkan Penanda Mikro Satelit. Jurnal Pemuliaan Tanaman Hutan 8(3) : 171-183.

Sumardi, Kartikawati NK, Prastyono dan Rimbawanto A. 2018. Seleksi dan Perolehan Genetik Pada Uji Keturunan Generasi Kedua Kayu Putih (Melaleucaca juputisub sp. cajuputi) Di Gunung Kidul. Jurnal Pemuliaan Tanaman Hutan 12(1) 65-73.

Surip, Indrioko S, Nirsatmanto A, dan Setyaji T. 2017. Pengaruh Seleksi Terhadap Perolehan Genetik Pada Uji Keturunan Generasi Pertama (F-1) Jabon Merah (Anthocephalus macrophyllus Roxb.
Havil.) di Wonogiri. Jurnal Pemuliaan Tanaman Hutan 11(1), 183-194.

Wardani S, Wirnas D, dan Wahyu Y. 2015. Seleksi Segregan Gandum (Triticum aestivum L.) Pada Dataran Tinggi. Jurnal Agronomi Indonesia 43 (1) : 4551.

Zobel BJ, dan Talbert JT. 1984. Applied Forest Tree Improvement. John Willey and Sons, Inc. Canada.

Zulfikri, Hayati E dan Nasir M. 2015. Penampilan Fenotipik, Parameter Genetik Karakter Hasil dan Komponen Hasil Tanaman Melon (Cucumis melo). J. Floratek 10 (2): 1-11. 